\title{
Interactions between prescription drugs in hospitalized geriatric patients
}

\author{
Erika Palacios-Rosas ${ }^{1 *}$, Alejandra d. C. Castilla-Hernández ${ }^{2}$ \\ ${ }^{1}$ Departamento of Health Sciences; ${ }^{2}$ Department of Chemical-Biological Sciences. Universidad de las Américas Puebla, Puebla, Mexico
}

\begin{abstract}
Background: It is estimated that, on average, a hospitalized patient receives between six and ten medications simultaneousIy. Moreover, older adults present physiological changes typical of aging, polypharmacy, and polypathology. The above considerably increases the possibility of drug interactions. Objective: Detect potential drug interactions (PDI) in 49 clinical files of hospitalized geriatric patients in Puebla, Mexico. Material and methods: The platform drugs.com was used to analyze forty-nine clinical charts of hospitalized geriatric patients 65 years or older. Results: 185 different types of PDI were detected, affecting $85.7 \%$ of the patients; $18.5 \%$ of these with high severity, $71 \%$ moderate, and $10.5 \%$ low. The most frequent PDI found on five occasions was Ondansetron-Tramadol, considered as serious. The most frequent drug involved was dexamethasone, repeating seventeen times, and causing nineteen PDIs. Conclusions: It is important to exercise pharmacovigilance in hospitalized geriatric patients to prevent the appearance of adverse reactions associated with drug interactions.
\end{abstract}

Key words: Medication errors. Geriatrics. Polypharmacy. Drug interactions. Drug prescriptions.

\section{Introduction}

The estimation is that by 2050 the global population of older adults will increase to $22 \%$ of the total population ${ }^{1}$. Human aging is a complex biological phenomenon that involves several changes and adaptations of the organism, causing the presence of chronic diseases to increase, and with it, the intake of medications ${ }^{2}$. Therefore, it is necessary to monitor the number and the class of medications that the geriatric patient consumes ${ }^{3}$.

The World Health Organization defines pharmacovigilance as the science and activity related to detecting, assessing, understanding, and preventing possible adverse effects that may be brought about by medications or any problems presented concerning them ${ }^{4}$. Pharmacovigilance provides knowledge of possible adverse effects of medications to reduce any harmful effects on the patient ${ }^{5-7}$. Medication errors are any preventable incident that can lead to inappropriate use of them ${ }^{8}$. At present, drug interactions may increase morbimortality in patients by decreasing the effectiveness of treatment or causing adverse events ${ }^{9}$.

Polypharmacy, common in older adults, can increase the presence of drug interactions, detected when there is a different response other than that expected when administered alone ${ }^{10,11}$. Potential drug interactions (PDI) in the elderly during hospitalization can be very common, requiring that they be monitored and cared for by a team of health personnel, especially if they suffer from a chronic disease or are on a polypharmaceutical treatment.

All health personnel have an important role in patient care, closely linked to knowledge of pharmacological

\section{Correspondence:}

*Erika Palacios-Rosas

E-mail: erika.palacios@udlap.mx
Available online: $18-10-2021$

Date of reception: 22-03-2021

Date of acceptance: 20-05-2021 DOI: 10.24875/RMU.21000021
Medicina Universitaria. 2021;23(3):80-84 www.medicinauniversitaria.org

1665-5796/@ 2021 Universidad Autónoma de Nuevo León. Published by Permanyer. This is an open access article under the CC BY-NC-ND license (http://creativecommons.org/licenses/by-nc-nd/4.0/). 
aspects $^{12}$. Knowledge of drug interactions and their adverse reactions is key in understanding their possible synergistic or antagonistic effects, favoring the rational prescription process ${ }^{13}$.

Rational polypharmacy implies the use of effective drugs to improve the health and well-being of the patient ${ }^{14}$. The Beers criteria are a useful tool for rational polypharmacy and for reducing adverse effects. These criteria are a detailed list of drugs that the American Geriatrics Society provides to improve drug selection in the elderly ${ }^{15}$.

This study aims to detect and evaluate the severity of potential drug-drug interactions in geriatric patients hospitalized in a private hospital in Mexico.

\section{Material and methods}

A descriptive, cross-sectional, and prospective study was carried out in a private hospital in Puebla, Mexico, from January through February 2020. This study was based on an analysis of 49 clinical charts of hospitalized patients aged 65 or older. The evaluation of the charts was done with the previous approval of the Ethics and Research Committee and with the signing of data confidentiality agreements. Data were extracted on age, gender, diagnosis, and medications consumed. To identify potential drug interactions (PDI), the drugs.com tool "Interactions Checker" was used. This is considered one of the best tools for disseminating pharmaceutical knowledge, providing descriptions of the severity of drug interactions according to evidence of interaction of clinical relevance in its database endorsed by Micromedex, Facts and Comparisons, and Multum ${ }^{16}$.

The data were analyzed through descriptive statistics using the Minitab version 19 software. We defined prevalence and frequency to obtain percentages, means, and standard deviation. $p$-value was calculated to obtain the correlation analysis between the number of prescribed medications and the presence of PDI.

Finally, the Beers criteria, a detailed list of drugs that the American Geriatrics Society provides ${ }^{15}$, were examined to assess whether any of the medications consumed by the population of this study were not recommended for this age group.

\section{Results}

The average age of the patients was $79 \pm 6.98$ years, with a range between 66 and 90 years; $44.8 \%$ were male and $55.2 \%$ were female.
The five most frequent diagnoses presented were pain of oncological origin (32.6\%), arterial hypertension $(16.3 \%)$, type II diabetes mellitus (12.2\%), hypothyroidism (8.1\%), and diverticular disease (6.1\%).

Of the 49 registered geriatric patients, $42(85.7 \%)$ showed signs of at least one PDI. A total of 185 different types of PDI were found and reported on 265 occasions, $18.5 \%$ of which were classified as high, $71 \%$ as moderate, and $10.5 \%$ as low severity. The drugs most frequently implicated in PDI were dexamethasone (6.4\%, 17 times), ciprofloxacin $(4.9 \%, 13$ times), omeprazole (4.5\%, 12 times), losartan (4.5\%, 12 times), and ondansetron (4.1\%, 11 times). The ten main PDIs found are detailed in table 1, while the ten high-severity PDIs are described in table 2.

Regarding diagnosis, table 3 details the PDIs found by diagnosis and their severity, while table 4 shows the high-severity PDIs found in the above diagnoses.

No statistically significant relationship was found between the number of prescribed medications and the presence of PDIs in the patients studied.

Evaluating the medications consumed with the Beers criteria, ketorolac was found as a non-prescription medication in six patients. Its possible adverse effect was to increase the risk of gastrointestinal bleeding.

It is important to note that upon detecting a PDI or medications that were not appropriate for the patient's treatment, the treating physician was notified and provided with information about the possible interactions and their effects. The treating physician is the one who decided to stop, change, or continue the medication. During the time of this research, no health problems were reported related to the presence of drug interactions. The hospital pharmacovigilance area monitors patients with PDI and, in case of high severity, sends a notification to the director of clinical services, the chief of admissions, and the nursing supervisor on duty. In all the cases studied where a possible high severity interaction was found, the treating physicians decided to change the medication; these new prescriptions were evaluated, and no PDIs were found.

\section{Discussion}

The geriatric population was chosen for this study since these patients are frequently forced to use more than one medication because they suffer from chronic diseases such as hypertension, diabetes, or osteoporosis, among others. This polypharmacy is a risk factor for presenting drug interactions ${ }^{17}$. 
Table 1. Potential drug interactions found more frequently

\begin{tabular}{|l|l|l|l|}
\hline $\begin{array}{l}\text { Potential drug-drug } \\
\text { interaction }\end{array}$ & n & Severity & Possible effect \\
\hline Ondansetron-Tramadol & 5 & H & $\begin{array}{l}\text { Increases the risk of a serotoninergic syndrome, which can induce symptoms such } \\
\text { as confusion, hallucination, and seizures. Can cause irregular heart rhythm }\end{array}$ \\
\hline Furosemide - Hydrocortisone & 4 & M & $\begin{array}{l}\text { May increase the risk of hypokalemia. The patient could experience loss of } \\
\text { appetite, weakness, or confusion }\end{array}$ \\
\hline Furosemide - Omeprazole & 4 & M & $\begin{array}{l}\text { The use of proton pump inhibitors in combination with medicines like furosemide } \\
\text { can cause hypomagnesemia }\end{array}$ \\
\hline Omeprazole - Parecoxib & 3 & L & Can increase the plasma concentration of omeprazole \\
\hline Ciprofloxacin - Ondansetron & 3 & M & May cause additive effects and increase the risk of ventricular arrhythmias \\
\hline Ondansetron - Mirtazapine & 3 & H & Increases the risk of a serotoninergic syndrome \\
\hline Furosemide - Dexamethasone & 2 & M & It can cause muscle pain, cramps, loss of appetite, and weakness \\
\hline Dexamethasone - Losartan & 2 & M & The effects of antihypertensive drugs are antagonized \\
\hline Ceftriaxone - Furosemide & 2 & M & May potentiate the nephrotoxicity of some cephalosporins. \\
\hline Enoxaparin - Parecoxib & 2 & M & It may increase the risk of gastrointestinal bleeding complications \\
\hline
\end{tabular}

H: hight; L: low; M: moderate.

Table 2. Potential drug interaction of high severity found more frequently

\begin{tabular}{|l|l|l|}
\hline PDI & $\mathbf{n}$ & Effects \\
\hline Ondansetron - Tramadol & 5 & Increases the risk of serotoninergic syndrome \\
\hline Ondansetron - Mirtazapine & 3 & Increases the risk of serotoninergic syndrome \\
\hline Ketorolac - Enoxaparin & 2 & Increased risk of developing epidural hematoma \\
\hline Clonazepam - Tramadol & 2 & It can lead to serious side effects, including respiratory distress, coma, and even death \\
\hline Trimebutine - Telmisartan & 1 & It can increase the risk of hypokalemia \\
\hline Clopidogrel - Omeprazole & 1 & The effectiveness of clopidogrel is reduced \\
\hline Alprazolam - Tramadol & 1 & It can cause sedation, coma, and death \\
\hline Ketorolac - Parecoxib & 1 & Ketorolac with other anti-inflammatories causes gastrointestinal inflammation \\
\hline Amiodarone - Furosemide & 1 & Increases the risk of ventricular arrhythmias \\
\hline Hydrocortisone - Levofloxacin & 1 & $\begin{array}{l}\text { Pain, inflammation in the ankle and shoulder. May potentiate the risk of tendinitis and tendon } \\
\text { rupture. }\end{array}$ \\
\hline
\end{tabular}

PDI: potential drug interaction.

In an observational study conducted on 438 older adults, 193 PDIs were found, 41 of high severity (21.2\%), 135 moderate $(70 \%)$, and 17 of low severity $(8.8 \%)^{18}$. In this study, similar data were found, with the PDIs being most frequently those of moderate severity (71\%). In 2013, an investigation was conducted with 118 geriatric patients with drug-related problems (DRPs). The highest percentage of these was due to PDIs (117 cases,
$32.4 \%$ ), emphasizing the impact of PDIs on these patients $^{19}$.

That same year, in a sample of 2712 hospitalized geriatric patients, it was found that 1642 (60.5\%) were exposed to at least one PDI and, of those, $18.9 \%$ to a potentially serious one 20 . In this study, $85.7 \%$ of the patients were exposed to at least one PDI, $18.5 \%$ to a high severity PDI, $71 \%$ to moderate, 
Table 3. Interactions found by diagnosis and its severity

\begin{tabular}{|l|c|c|c|c|c|c|}
\hline \multirow{2}{*}{ Diagnosis } & \multicolumn{3}{|c|}{ Highseverity } & \multicolumn{2}{|c|}{$\begin{array}{c}\text { Moderate } \\
\text { severity }\end{array}$} & \multicolumn{2}{|c|}{$\begin{array}{c}\text { Low } \\
\text { severity }\end{array}$} \\
\cline { 2 - 8 } & $\mathbf{n}$ & $\%$ & $\mathbf{n}$ & $\%$ & $\mathbf{n}$ & $\%$ \\
\hline Oncological pain & 16 & 36.3 & 25 & 56.8 & 3 & 6.8 \\
\hline Hypertension & 4 & 20 & 13 & 65 & 3 & 15 \\
\hline $\begin{array}{l}\text { Diabetes } \\
\text { Mellitus II }\end{array}$ & 0 & 0 & 8 & 100 & 0 & 0 \\
\hline $\begin{array}{l}\text { Hypothyroidism } \\
\text { Diverticular }\end{array}$ & 6 & 13.9 & 32 & 74.4 & 5 & 11.6 \\
\hline disease & 2 & 13.3 & 13 & 86.6 & 0 & 0 \\
\hline
\end{tabular}

Table 4. High severity potential drug interactions found in the five most frequent diagnoses

\begin{tabular}{|c|c|c|}
\hline Potential high severity drug interaction & $\mathbf{n}$ & Diagnosis \\
\hline Ondansetron - Tramadol & 2 & $\mathrm{OP}$ \\
\hline Ondansetron - Mirtazapine & 2 & HTA, DD \\
\hline Metoclopramide - Tramadol & 1 & $\mathrm{OP}$ \\
\hline Ciprofloxacin - Hydrocortisone & 2 & $\mathrm{OP}$ \\
\hline Amlodipine - Simvastatin & 1 & HTA, OP \\
\hline Amitriptyline - Ondansetron & 1 & HTA, OP, \\
\hline Trimethoprim - Losartan & 1 & HTA, OP, HYP \\
\hline Dexamethasone - Thalidomide & 1 & OP, HYP \\
\hline Dexamethasone - 0xycodone & 1 & OP, HYP \\
\hline Morphine - Oxycodone & 1 & OP, HYP \\
\hline Acetylsalicylic Acid - Enoxaparin & 1 & OP, HYP \\
\hline Ketorolac - Parecoxib & 1 & $\mathrm{OP}$ \\
\hline Hydrocortisone - Levofloxacin & 1 & OP \\
\hline Ciprofloxacin - Prednisone & 1 & $\mathrm{OP}$ \\
\hline Ketorolac - Enoxaparin & 1 & $\mathrm{DD}$ \\
\hline Clonazepam - Tramadol & 1 & $\mathrm{OP}$ \\
\hline
\end{tabular}

DD: diverticular disease; HTA: hypertension; HYP: hypothyroidism; OP: oncological pain.

and $10.5 \%$ to low. All these studies highlight the importance of monitoring the treatment of geriatric patients.

In 2013, in Belgium, the presence of 304 DRPs was detected in 100 geriatric patients; $20 \%$ showed signs of PDIs, and among the medications most involved were painkillers $(11 \%)^{21}$. In this study, analgesics were involved in $15 \%$ of the PDIs. Because they reduce or relieve pain, these drugs are frequently used, and on many occasions, no care is taken with their prescription or intake, thus favoring the appearance of a PDI.

In 2017, there was a study with 3055 adults between 70 and 79 years of age, where $25.1 \%$ of the patients showed signs of one or more PDIs, with nonsteroidal anti-inflammatory drugs (NSAIDs) being the drugs most involved $^{22}$. In this study, NSAIDs were also the drugs most involved in the development of PDIs. It is important to remember that NSAIDs should be used with caution when treating pain in geriatric patients due to the possibility of developing peptic ulcers after their prolonged use ${ }^{23}$.

Due to the amount of PDIs found, it is unavoidable to think of actions that can minimize their effects. Some authors suggest observing signs and symptoms of patients, monitoring the therapeutic response, and checking administration schedules to avoid combinations of medications ${ }^{24}$. Similarly, it is proposed that hospitals should have a pharmacovigilance department that can provide a continuing education plan on drug information to ensure patient safety ${ }^{25}$.

Medications, being active chemical substances, provide significant advantages to the health of society, but they can also produce or trigger diseases, disabilities, or even death ${ }^{26,27}$. For this reason, pharmacological treatment in the geriatric population must be carried out by a medical specialist, who, together with the support and advice of the pharmacist, can evaluate the risk/ benefit of each medicine and thus provide the patient with better medication.

\section{Study limitations}

Data collection time was limited. However, a large number of interactions were found.

\section{Conclusions}

The results of this research contribute to improving the health and safety of older adults. This study aims to provide health professionals with valuable information on the importance of a rational prescription of drugs in older adults, highlighting the care that must be taken in the polypharmacy of these patients to detect possible drug interactions and prevent their adverse effects. Drug interactions are common among geriatric patients, so more studies like this are needed to ensure better drug management. 


\section{Acknowledgments}

The authors thank the Hospital Ángeles Puebla for the facilities provided to carry out this study.

\section{Conflict of interests}

The authors declare there are no conflicts of interest.

\section{Funding}

The authors declare there was no funding.

\section{Ethical disclosures}

Protection of human and animal subjects. The authors declare that no experiments were performed on humans or animals for this study.

Confidentiality of data. The authors declare that they have followed the protocols of their work center on the publication of patient data.

Right to privacy and informed consent. The authors declare that no patient data appear in this article.

\section{References}

1. World Health Organization. Pharmacovigilance. Geneva: World Health Organization; 2020. Available from: https://www.paho.org/hq/index. php?option=com_content\&view=article\&id=7895:2012-pharmacovigilance\&ltemid=39715\&lang=es. [Last accessed on 2020 Sep 10].

2. Woulfe KC, Bruns DR. From pediatrics to geriatrics: mechanisms of heart failure across the life-course. J Mol Cell Cardiol. 2019;126:70-6.

3. Soares M, Oliveira C. Drug interactions and adverse reactions to medications in polypharmacy in older adults: an integrative review. Latin Am Enferm Magaz. 2016;24:e2800.

4. World Health Organization. Promotion of the Rational Use of the Medicines: central Components. Geneva: World Health Organization; 2002. Available from: https://www.apps.who.int/iris/bitstream/handle/10665/67532/WHO_EDM_2002.3_spa.pdf;jsessionid=91237AA798FD7431F63BD178C65C7BD4? sequence $=1$. [Last accessed on 2020 Sep 10].

5. Furlan G, Caduff-Janosa P, Sottosanti L, Cappello E, Valdiserra G, Tuccori M. Drug Safety in geriatric patients: current status and proposed way forward. Drug Saf. 2020;43:853-66.

6. Sferrazza G, Nicotera G, Pierimarchi P. Suspected adverse drug reactions (ADRs) trends in older Italian patients: an analysis from the nationa pharmacovigilance network. Aging Clin Exp Res. 2019;33:1683-7.
7. Lynch S. Pharmacological Interactions. MSD Handbook; 2019. Available from: https://www.msdmanuals.com/es-pe/professional/farmacolog\%C3\%ADa-cl\%C3\%ADnica/factores-que-afectan-la-respuesta-a-los-f\%C3\%A1rmacos/interacciones-farmacol\%C3\%B3gicas. [Last accessed on 2020 Sep 10].

8. National Coordinating Council for Medication Error Reporting and Prevention (NCCMERP). About Medication Errors; 2016. Available from: https://www.nccmerp.org/about-medication-errors. [Last accessed on 2020 Sep 10].

9. Aiezza M, Bresciani A, Guglielmi G, Massa M, Tortori E, Marfella R et al. Medication review versus usual care to improve drug therapies in hospitalised older patients admitted to internal medicine wards. Eur $\mathrm{J}$ Hosp Pharm. 2021;28:160-4.

10. Zhang L, Reif A, Du Rietz E, Lagerberg T, Butwicka A, D'Onofrio BM, et al. Comedication and polypharmacy with ADHD medications in adults: a Swedish nationwide study. J Attent Disord. 2021;25(11):1519-28.

11. Rodrigues AD, Lai $Y$, Shen $H$, Varma MV, Rowland A, Oswald S. Induction of human intestinal and hepatic organic anion transporting polypeptides: where is the evidence for its relevance in drug-drug interactions? Drug Metab Disposit. 2020;48:205-16.

12. Romero K. El conocimiento de la farmacología en el profesional de enfermería. Enferm Inv. 2018;3:95-104.

13. Reyes Alfaro CE, Castillo Saavedra EF, Castillo Viera SF. Nivel de conocimiento de la enfermera sobre la administración de medicamentos e interacciones medicamentosas potenciales en la Unidad de Cuidados intensivos del hospital regional docente de trujillo 2010. UCV. 2013;5:80-7.

14. Yoon SK, Okyere BA, Strasser D. Polypharmacy and rational prescribing: changing the culture of medicine one patient at a time. Curr Phys Med Rehabil Rep. 2019;7:141-58.

15. American Geriatrics Society. Updated AGS beers criteria® for potentially inappropriate medication use in older adults. J Am Geriat Soc. 2019;67:674-94.

16. Milá S. Spanish; 2008. Available from: http://www.elsevier.es/es-revista-offarm-4-articulo-www-drugs-com-13114939? referer=buscadorJan. [Last accessed on $2021 \mathrm{Apr} 27$ ].

17. Novaes PH, Da Cruz DT, Lucchetti AL, Leite IC, Lucchetti G. The "iatrogenic triad": polypharmacy, drug-drug interactions, and potentially inappropriate medications in older adults. Int J Clin Pharm. 2017;39:818-25.

18. Serra Urra M, German Meliz J. Polypharmacy in older adults. Haban J Med Sci. 2013:12:142-51.

19. Venturini CD, Engroff P, Ely LS, Zago LF, Schroester G, Gomes I. Gender differences, polypharmacy, and potential pharmacological interactions in the elderly. Clinics. 2011;66:1867-72.

20. Yeoh TT, Si P, Chew L. The impact of medication therapy management in older oncology patients. Support Care Cancer. 2013;21:1287-93.

21. Pasina L, Djade CD, Nobili A, Tettamanti M, Franchi C, Salerno F, et al. Drug-drug interactions in a cohort of hospitalized elderly patients. Pharmacoepidemiol Drug Saf. 2013;22:1054-60.

22. Somers A, Robays H, De Paepe P, Van Maele G, Perehudoff K, Petrovic M. Evaluation of clinical pharmacist recommendations in the geriatric ward of a Belgian university hospital. Clin Interv Aging 2013;8:703-9.

23. Emektar E, Dağar S, Çorbacıoğlu ŞK, Uzunosmanoğlu H, Uzman M, Karaatlı $\mathrm{RH}$, et al. Predictors of mortality in geriatric patients with upper gastrointestinal bleeding. Eur J Emerg Med. 2020;19:197-202.

24. Hanlon JT, Perera S, Newman AB, Thorpe JM, Donohue JM, Simonsick EM, et al. Potential drug-drug and drug-disease interactions in well-functioning community-dwelling older adults. J Clin Pharm Ther. 2017:42:228-33.

25. Fontenele Lima RE, Cassiani De Bortoli HS. Interacciones medicamentosas potenciales en pacientes de una unidad de terapia intensiva de un hospital universitario. Rev Latino Am Enferm. 2009:17:222-7.

26. Şavlı E. The importance of pharmacovigilance and ecopharmacovigilance in nursing education. Ordu Univ J Nurs Stud. 2019;2:70-7.

27. Álpizar Cortes JE, Angeles Lozano KL, Ávila Ballesteros D, Calva LL, Cano WD, Olvera EG, et al. Identification of potential drug interactions in geriatric patients. JONNPR. 2020;5:998-1009. 